\title{
Context Adaptation and Marine Engineering English Translation
}

\author{
Wang Ranran \\ Foreign Department Tianjin Maritime College, Tianjin 300350, China \\ wrrtianjin@163.com
}

\begin{abstract}
On the basis of Verschueren's theory of contextual adaptation, the paper discusses the influences of context adaptation to marine engineering English translation, especially to the restriction of word meaning. Translators should choose the word meaning complying with the scientific context of marine engineering English, and pay attention to the assimilation, fusion and implicit phenomenon of words in translation, so as to effectively guide and promote our translation and teaching.
\end{abstract}

Index Terms - context adaptation; marine engineering English; translation.

\section{Introduction}

Context occupies an important position and of great values in modern linguistics the field. It is an important content in disciplines as pragmatics, social linguistics, translation, semantics, rhetoric, etc. Linguists both home and abroad has made many wonderful descriptions and classifications of context [1,2]. In 1999, Verschueren reclassified context in his new book "Understanding Pragmatics": communicative context and linguistic context. He stated the dynamic process of context adaptation and language use from a brand-new angle of view. During the process of translation, the translator should choose the appropriate language adapting to different language structures and different context so as to gain the best effect of translation. In recent years, linguists have had intensive studies about context adaptation and translation strategies, but not for marine engineering English translation strategy. As an examination subject of marine engineering majors in navigation colleges to gain professional certificates of competency, marine engineering English has a lot of difficulties in translation. Many students know all the words' dictionary meanings, but still can't translate them into Chinese smoothly. Based on Verschueren's theory of contextual adaptation, the paper discusses the influences of context adaptation to marine engineering English translation, especially to the restriction of word meaning, so as to effectively guide and promote our translation and teaching.

\section{II . Context adaptation}

Verschuren (1999) divides context into communicative context and linguistic context. Context adaptation refers to: language choice must be adapted to the communicative context and linguistic context in the process of language use. Communicative context includes the language users, the mental world, the social world and the physical world.[3] Language context is also called linguistic channel, mainly includes three aspects: cohesion, inter-textuality and sequencing. Cohesion refers to the use of conjunctions, anaphora, self-reference, logical relation, ellipsis, numbers, contrast, repetition, replacement and similar structure to realize the discourse semantic correlation; inter-textuality refers to that the language is affected and restricted by the pragmatic styles or situational factors like topics and style types; sequencing refers to paying attention to the discourse logics when choosing a language according to contextsemantic relations, in order to arrange the discourse.

Verschuren assumes that language users are able to make the proper choice constantly in the process of language use, because of language variability, negotiability and adaptability. Language compliance means that it can let users make flexible choices from different language projects, so as to meet the features of communication need. The three features of language complement each other, inseparable, among which compliance is the most important one.

\section{Restriction of Context Adaptation on Word Meanings}

Marine engineering English belongs to ESP (English for Special Purpose), which is a professional course melting both the professional marine engineering knowledge and English language skills. Marine engineering English discourse, as a kind of scientific discourse, is characterized by its objective, clarity and accuracy.[4] The objective of this kind of literary works is pragmatic, thus requiring the translation faithful to the facts as far as possible, not only accurate, smooth, and also simple, professional, and conforming to the Chinese language habits and features. In the translation of marine engineering English, due to the extended meanings, the change of concept connotation and denotation, the selection of word meaning in translation is restricted by the context adaptation.

The same word may have different meanings in different context, which will also be assimilated, fused or concealed. Context adaptation can narrow the word meaning scope of a collocation farthest, making the translation easier.

\section{A) Choice of Word-meaning}

Choice of meaning means to choose the right meaning from multiple dictionary meanings of a word. There are many polysemy phenomenons in English, the language in life is full of ambiguity and ellipsis, how to eliminate ambiguity and how to supplement information omitted is dependent on context to a large extent. In the process of translation, to choose the correct one from multiple meanings must comply with the contextual relationship, which could make it conform to the 
original context and reflect the original style. For example, the Chinese dictionary meanings of "power" include "rate of work, strength, ability, regime, force, exponentiation, electricity", etc. Let's look at the following few sentences with "power" in marine engineering English and their Chinese translations:

1) The power consumed is therefore the product of voltage and current.

$$
\text { power }=\text { rate of work }
$$

2) There are a few common arrangements for using hydraulic power.

hydraulic power = hydraulic energy

3) The complete electrical plant on board ship is made up of power generation equipment, a distribution system and many power utilizing devices.

power generation equipment = electricity generation equipment; power utilizing devices = electric equipment, consumer

As for the example above, according to "the product of voltage and current" in sentence 1) we can easily infer that "power" should be translated into "rate of work"; according to the collocation of "hydraulic power", we can also deduce that "power" should be translated into "energy"; as for "power generation equipment" and "power utilizing devices" in sentence 3), some translators may translate them as "electricity generation equipment" and "consumer", which doesn't conform with "complete electrical plant on board ship" in the sentence. Complying with professional knowledge, we should know the whole electrical system is made up of electricity generation equipment, distribution system and electrical equipment, so that the word "power" should be translated as “电”. These three meanings are the most commonly used semantic meanings in marine engineering English. Translators need to determine the word's correct meaning complying with the marine engineering professional knowledge and the scientific context.

\section{B) Assimilation}

Assimilation refers to converting the words or phrases of lower degree of generalization into appropriate words or phrases of higher degree of generalization in marine engineering English, so that translators can find a new word meaning whose connotation preserving and containing the meaning of the original word. For example,

4) Maintenance requirements for this equipment are usually minimal but regular inspection and servicing should be undertaken.

$$
\text { servicing }=\text { maintain }
$$

5) All deck machinery is exposed to the most severe aspects of the elements.

the most severe aspects of the elements = the worst weather condition
6) As the ship moves through the water, the angle of the rudder at the stern determines the direction it will move.

$$
\begin{aligned}
& \text { moves through the water = sails in the sea; } \\
& \text { the direction it will move }=\text { the course it will sail at }
\end{aligned}
$$

\begin{tabular}{|c|c|c|}
\hline 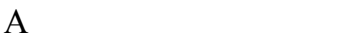 & & B \\
\hline $\begin{array}{l}\text { servicing } \\
\text { the most severe aspects }\end{array}$ & $\rightarrow$ & maintain \\
\hline of the elements & $\rightarrow$ & the worst weather condition \\
\hline oves through the water & $\rightarrow$ & sails in the sea; \\
\hline
\end{tabular}

The assimilation phenomenon in translations above can be clearly represented as:

Obviously, the word meanings of A part is contained in those of $\mathrm{B}, \mathrm{A} \subset \mathrm{B}$. If the characters with bullet points in 4), 5), 6 ) are changed into the ones in A, the whole translation will be unprofessional and even incomprehensible. On account of the above situation, assimilation translation not only makes the translation more concise, but also conforms to the requirements of the scientific style of marine engineering English.

\section{C) Fusion}

Fusion phenomenon means a few words or phrases in some specific collocation fused to form a complete concept which can't be translated separately. Therefore, translators should seize the main idea and the whole meaning of the sentence after fusion, not word for word translation. For example,

7) Say for example if a ship has three generators on board, two are used under normal working conditions and one is kept as standby. Wherever a requirement to service a running generator arises, the standby generator is brought in line and the desired generator is taken off line.

Wherever a requirement to service a running generator arises $=$ When there is a requirement of change the running generator into another one;

the desired generator is taken off line = the running generator is brought out of the synchronization

8) In carrying out these duties the oil is exposed to contamination by products of combustion.

is exposed to contamination by products of combustion $=$ is contaminated by the combustion outcome

\section{D) Implicit}

Implicit phenomenon means that in certain collocations, the meanings of some words are in the prevalent position, while the meanings of some words are almost blanking. Therefore, translators should comply with the specification of scientific papers in translation, and there is no need to translate the meaning of blanking words. For example,

9) More number of generators are used to facilitate load sharing and to prevent wear down due to excessive load. 


\section{facilitate load sharing = load sharing}

In the above sentence, the meaning of "load sharing" accounts for absolute advantage, and there is no need to translate the meaning of "facilitate". Thus, "facilitate load sharing" is translated into "load sharing".

\section{IV . Conclusion}

According to contextual adaptation, the choice of language should be a dynamic adaptation in the translation process, the adaptation should be changed according to different contexts. Translation process necessarily involves the reconstruction process of the target language, and the refractory of target language is a process for the translator to make a dynamic adaptation between the original language context and language structures. In marine engineering English translation process, translators should comply with the marine engineering English context to choose the appropriate scientific meanings, they should also pay attention to assimilation, fusion and implicit phenomenon of the words in translation, so as to effectively guide and promote our translation and teaching.

\section{References}

[1] H . Leo , The Pragmatics of Translation . Shanghai : Shanghai Foreign Language Education Press, 2001.

[2] J. Li, K.H. Liao, "On Adaptation of Cultural Context and Translation Strategies", Language and Translation (Chinese), vol.82, no.2, pp. 49-52, May 2005.

[3] J.Verschuren, Understanding Pragmatics, London, Arnold, 1999.

[4] M.F. Zhang, G.W. Huang, "A Text Linguistic APProach to Translation Studies”, Chinese Translators Journal, vol.23, no.3, May 2002. 